\title{
Kapitalizm ve Ölüm Dürtüsü
}

\author{
Gözde Aykut \\ Arș. Gör. \\ Afyon Kocatepe Üniversitesi \\ Fen Edebiyat Fakültesi Sosyoloji Bölümü \\ gozde.aykut03@gmail.com \\ Orcid: 0000000317345147
}

\section{Han, B. C. (2020). Kapitalizm ve Ölüm Dürtüsü. İstanbul: İnka,127 sayfa, ISBN:978-60580295-8-3}

Çevirisi Çağlar Tanyeri tarafından yapılan Byung-Chul Han'ın en son kitaplarından biri olan Kapitalizm ve Ölüm Dürtüsü günümüzdeki büyüme sürecini bir problematiğe dökerek ele alıyor. Tam olarak nerede sonlanacağını bilmediğimiz ama hızla devam edişinden emin olduğumuz üretim süreci, aslında bir yıkımdır. Yıkımın kaynağını üretim süreci ile birlikte bireyin kendisine yabancılaşması temsil etmektedir. Freud, Kültürdeki Huzursuzluk adlı çalışmasında insanın vahşi bir canavar olarak saldırgan bir tutuma sahip olduğundan bahseder. Hatta saldırgan eğilimlerinin altındaki sebebi içindeki ölüm dürtüsüne bağlar. Han, Freud'un bu söylemlerinden yola çıkarak kapitalizm ve insanın içindeki ölüm dürtüsü arasında bir ilişki kurmaya çalışır. Freud, Kültürdeki Huzursuzluk adlı çalışmasını tamamladıktan birkaç ay sonra ekonomik kriz patlak vermiş ve bu kriz ile birlikte insanın saldırgan tutumu açığa çıkmıştır. Han, kapitalizmdeki bu yıkıcılığı bireyin içerisindeki ölüm dürtüsü ile ilişkilendirmeyi mantıkı görür ve burada önemli bir sorunun peşine düşer. Kapitalizmin yıkıcılığını sadece ölüm dürtüsü ile açıklamak mümkün müdür, yoksa ölüm dürtüsünü anlatabilecek başka kavramlara intiyaç var mıdır? Han, soruyu Maris üzerinden tartışarak, kapitalizmin büyüme arzusunun bir ölüm dürtüsü olduğunu belirtir. Bir diğer önemli soru ise " kapitalizmi sermaye birikimine zorlayan şey nedir?" (s.11). Cevap: Ölüm. Ölüm, üretim ve büyüme arzusunu ortaya çıkarır. Burada biriktirilmeye çalışan servet ölüm bağlamında anlam kazanır. Çünkü bireyin sermaye biriktirme arzusu ile ölüme karşı koyabilme inancı arasında tarihsel bir arka plan vardır. Biriktirilmiş olan servet, bireyde ölümsüzlük ve güç sarhoşluğu duygusunu uyandıır. Sermaye artıkça ölüm, anlam kaybına uğrar. Tam burada Han'ın diğer kitaplarında değindiği performans öznesi kavramı devreye girer. Yani günümüz bireylerinin efendisiz köleler haline gelmeleri durumu. Fakat Kapitalizm ve Ölüm Dürtüsü adlı kitabında bunun yerine performans prensibi kavramını kullanmayı tercih etmiştir. Bu prensip insanı kendine yabancı kılmaktadır. Yabancılaşmadan ve ölümden kurtulmanın 
tek yolu yaşamı feda etmektir. Genellikle ölümle mücadelede an kaybolur. Geçmişe ve geleceğe yönelme ise daha fazladır. Aslında Han, ölümü ve yaşamı arzulama arasında bir paradoks olduğunu ifade eder. "Ölmek için fazlasıyla canlıyız ve yaşamak için de fazlasıyla ölü" (s.22).

Han, Antoni Negri ile Berliner Schaubühne'de yapmış olduğu bir tartışmada Negri'nin aksine devrimin sonunun geldiğini belirtir. Iddiasını disiplin ve sanayi toplumunun iktidara dair bakış açısı ile neoliberal egemenlik sisteminin iktidara yaklaşımı arasındaki fark üzerinden temellendirir. Disiplinci iktidarda sömürü, bireyi protestoya yönlendirir. Fakat Neoliberal iktidarda direnişi mümkün kılan bir karşı taraf yoktur. Neoliberal işçi hiçbir zaman sanayi toplumu işçisinin yapmayı arzuladığı devrimi mümkün kılacak bir sistem içerisinde olmamıştır. Çünkü günümüz işçisi kendi şirketinde ve kendi girişimci düzeninde sadece kendini sömürendir. Böyle bir ortamda devrim kime karşı yapılacaktır. Elbette bir iktidarın olmadığından bahsetmek mümkün değildir. Burada önemli olan insanların egemenlik ilişkilerine kendilerinden tabi olmalarıdır. Iktidarın bireyi gönülü köle hale getirebilmesi bu anlamda bir başarıdır. Günümüzde bireyin kendine yabancılaşması Marksist bakış açısıyla açıklanamayacak kadar karmaşık ve karşılığı olmayan bir şeydir. Han, insanın içinde bulunduğu bu çıkmazı Amerikalı sanatçı Jenny Holzer'ın "Protect me from what I want" ${ }^{1}$ sözüyle destekler. Tüm bunlardan yola çıkarak komünizm metalaşmış ve devrim olasılık dışı kalmıştır.

Günümüzde birey, bütüncül bir sömürülüş içerisindedir. " Müşterinin Yaşam Boyu Değeri " olarak tanımlar Han bu durumu. Sadece kapitalizmin bu denli büyüme isteği değil, aynı zamanda hızla artan dijitalleşmede insan yaşamını sömürmektedir. Dolayısıyla kapitalizm ve dijitalleşme iç içe geçmiş sömürü unsurlarıdır. İçinde bulunduğumuz kapitalist süreci hiper kapitalizm olarak adlandıran Han, bunun mabedini ise Apple'ın New York'taki Flagship-Store'u olarak görür. Öyle ki Apple -Shop ve Kâbe arasında bir egemenlik ayrımına gider. Apple-Shop içerisine herkesin özgürce girebildiği bir yer olması dolayısıyla şeffaflığı, ayrıca sınırsız özgürlük ve iletişimi temsil eder. Kâbe'de ise durum bundan farklıdır. İçeriye sadece din adamları girebilir. İlkinde açma diğerinde ise kapatma egemenliği üzerine bir düzen vardır. Han, açma egemenliğinin daha fazla özgürlük ve alan sunuyor olmasından dolayı daha etkili olduğunu savunur. Daha etkili bir egemenlik ise Big Data sayesinde mümkün olmaktadır. Bu yönüyle Big Data iradenin kaydı anlamına gelmektedir. Verilerin sahibi olan, iradenin, iktidarın ve gücün sahibidir. Han, günümüzde hala George Büchner'in sözlerinin gücünü koruduğunu iddia eder. " Tanımadığımız güçler tarafından ipe çekilmiş kuklalarız bizler; hiçiz kendimiz, hiç! " (s. 35).

Han'ın anlatılarından yola çıkarak denebilir ki Big Data (Büyük Veri) ile Dijital Panoptikon arasında bir doğru orantı vardır. Hayatlarımız o denli dijitalleşmiştir ki yakında Smart City benzeri şehirlerde yaşamaya başlayacağız. Hayatımızın yakın gelecekte bu denli dijitalleşmesi doğrudan duygularımıza da etki edecek,

1 İstediğim şeyden koru beni. 
Dating-App (flört uygulaması) ile aşk ve seks meselelerinde daha verimli olmamı hedeflenecek. Dijitalleşme hayatımızda ciddi bir teşhirciliğe sebep olmuştur. Han, bu durumu pornografik teşhircilik olarak nitelendirir. Artan enformasyon ve iletişim daha fazla üretim ve büyüme isteği anlamına gelmektedir. Tüm bu olan biten içerisinde günümüz iktidarı, özgürlüğümüzü kısıtlamamakta yeni özgürlük alanları açmaktadır. Fakat buna rağmen bir özgürlük krizi yaşanmaktadır. Bunun temel sebebi ısrarla sömürülüyor olmamızdır. Han, Apple'ın 1984 yılında Super Bowl² sırasında ekranda beliren reklam spotunda Apple'ın Orwell'in gözetim toplumu ile kıyaslanmasını manidar bulur. Apple, Orwell'in gözetim devletinin bir parçası olmadığını iddia eder. Bu yönüyle haklıdır. Çünkü onun gözetim toplumundan kat ve kat daha denetimci ve gözetleme yetileri gelişmiş durumdadır. Şeffaflık ise gözetimin başka bir yönünü ifade eder. Şeffaflık, günümüzde enformasyon özgürlüğü bağlamında methediliyor. Bireyin kendisine bile şeffaf olamayacağı bir gerçek iken, "Post-Privacy" (mahremiyet sonrası) ideoloji özel alanı tamamen feda ederek şeffaflık isteği içerisine girmiştir. Birey üzerinden bu denli bir şeffaflık isteği ruhu yok eder. Şeffaflık toplumunun öznesi performans öznesidir ve bu özne, öz-sömürü ile karşı karşıyadır.

Bireyi performans öznesine yaklaştıran aynı zamanda performans öznesinin ne olduğunu bildiren şey dataizm ile ilgilidir. Günümüzün veri toplama çılgınlığının yeni adı dataizmdir. Vücut ısımızdan yürürken attığımız adımlara, kalori alımlarımızdan uyku düzenimize kadar her şey dataizmin bilgisi dahilindedir. Han, bu denli fazla verinin bireyler için faydalı olup olamayacağını sorgular. Fakat bu verilerden bireyi kendine bilgi çıkmaz. Ne kadar kapsamlı veriler olursa olsun tam anlamıyla bireyi anlatamaz. Veriler, performansın ötesine giden sorulara cevap veremez. Bireyin bilinç devinimleri, duygu değişimleri ile ilgili sorular cevapsız kalır. Ortaya sadece anlamsız bir boşluk çıkar. Anlamdan ve hakikatten yoksun bu veriler içinde önemli olanı önemsiz olandan ayırmakta zor bir iştir. Bu yönüyle Han, dataizm ve nihilizmi bir madalyonun iki yüzü olarak görür. Anlam ve bağıntıların olmadığı bir ilişkidir bu. Günümüz öznesi, bu anlam kaybı içerisinde bir boşluktadır. Han, bu iddiasını eziyet çektiren boşluk ifadesi ve Almanya'da yaşayan gençler üzerinden devam ettirmektedir. Milyonlarca genç koluna jilet atarak rahatlama yolunu tercih ediyor. İşin kötü tarafı kendine zarar verme yöntemi olan bu durum, bir anlam kazanma ve bağımlılık olma yönünde ilerliyor. Bu gençlerin hissettikleri içsel boşluk, utanç duygusu ve öz-sömürü onların hiçbir şey hissetmemelerine sebep olmuştur. Ancak vücutlarına çizik attıklarında bir şey hissedebiliyorlar ve bu onlarda anlam kazanıyor. Kendini bu denli yaralayanlarda göze çarpan en temel nokta, depresyon ve kaygı bozukluğu.

Günümüz performans öznesi, depresif ve narsist bir öznedir. Her şeyden önce kendi kendisi ile bir yarış içerisindedir. Asla bir tatmin noktasına ulaşamamaktadır. Her daim yorgun, suçluluk ve eksiklik duygusu içerisinde kaybolmuştur. Suçladığı hiç kimse ve hiçbir sistem ile yüzleşememekte, sürekli olarak kendine diş geçirmekte ve kendi içini oymaktadır. Han'ın diğer kitaplarında da ısrarla üze-

2 Amerikan futbol liginin final maçının adı. 
rinde durduğu olumsuzluğun bertaraf edilmesi hususu günümüzün önemli problemlerinden biridir. Her şeyin pürüzsüz hale getirilme arzusu bireyi yorar. Bu tipik bir performans öznesi özelliğidir. Han, bu öznenin iki şeyi tanıdığını iddia eder: işlevsel olmak ya da arıza yapmak. İnsanın içinde büyüttügü boşluk yüzünden kendini yenileme ve var etme çabası hiçbir zaman başarıya ulaşamayacak bir çabadır. Bu yüzden son dönemlerin modası olan selfieler, boş ve anlamsız biçimleri yansıtan ve bu duyguları kesinleştiren biçimlerdir. Han, burada intihar saldıııları ile kendini yaralama ve selfie (öz çekim) arasında bir anlam ilişkisi kurmaya çalışır. Paris'teki intihar saldırısı ile kendine zarar verme istediği içerisinde olan gençler arasında bir fark var mıdır? Ya da bu terör saldırılarını gerçekleştiren bireyler, kendi içindeki boşluğu doldurmak adına ve örselenmiş özdeğer duygusunu yeniden canlandırmak adına, bir yerleri bombalama ve yok etme gibi sapkın bir yolu seçmiş olabilirler mi? Han, bu soruya net bir cevap vermese de bir olasılık cümlesi kurar. " Bombayı patlatan düğmeye basmak, kamerayı çalıştıran düğmeye basmak gibi olabilir. Bu noktada hayali olan (Imaginare) hüküm sürmektedir, çünkü ayrımcılık ve umutsuzluktan oluşan gerçeklik yaşanmaya değer değildir artık " (s.61).

Homo sapiens ile akraba olan fakat bir homo sapiens olmayan, homo saliensler doğmuştur günümüzde. Bunlar insana dair bilgelik ve erdemden nasibini almamış, hoplayıp zıplayan insanlardır. Yorgunluktan muzdarip olan günümüz bireyi neden fotoğraf çekilirken ya da bir kamera gördüğünde hoplayıp zıplıyor? Bu onların yorgun değil, mutlu olmalarından kaynaklı bir durum mudur? Günümüzde çekilen fotoğraflarla eskiden çekilen fotoğraflar arasında bir kült değer problemi var. Bugün çekilen fotoğraflardaki insan yüzlerinde herhangi bir kült değer bulmak mümkün değil. Eski fotoğraflarda Han'ın ifadesiyle efendi pozlar verilirdi. Bireylerin poz verirken kendilerini sergilemeden ziyade anı biriktirme niyetleri vardı. Fakat artık sergi değeri kült değerinin önüne geçti. Bir nesnenin kült değeri, var olmasına bağlıdır sergilenmesine değil. Aslında tüm bunlar Han'ın biraz önce sorduğu sorulara bir cevap veriyor. İnsanlar kamera karşısında hoplayıp zıplıyor çünkü sergilenme çılgınlığı günümüzün bir başka problemi olmuş durumda.

Bireyin öz-sömürülüşünden Han, küresel bağlamda mültecilerin nereden geldiğini ve kapitalist sistemin zayıf bireyleri ve ülkeleri nasıl sömürdügünü tartışıyor. 2008' de yaşanan finans krizinde $A B$ devletleri batmak üzere olan bankaları kurtarmak için bir arada dururken aynı şeyi mülteci krizini çözmek ve insan hayatını kurtarmak için yapmamıştır. Fakat Han, Angela Merkel'in mülteci yardımlarına yönelik söylemini bunun dışında görür. Birçok ürünü elde etmek için var gücümüzle mücadele ediyoruz. Fakat elde etmeyi istediğimiz bu ürünlerin hammaddeleri çok ağır koşullar altında çıkarılıyor. Dahası Batı'nın bu refahı ağır koşullar altında çalışan insanların acısına dayanıyor. Bu noktada Batı'nın kendi çıkarları için geleceğine müdahalede bulunduğu birkaç ülkeden bahsetmek mümkündür: Fransa'nın 2013 yılında İslamcı teröristlerle mücadele ettiğini iddia ederek Maliye girmesi ve buradaki yeraltı zenginliklerine göz dikmesi, Avrupa'nın 2011'de Libya'da gerçekleştirdiği askeri müdahale ile ülkenin geldiği son durum ya da NATO'nun 1999'da BM yetkilendirmesi olmadan Kosova'yı bombalaması gibi. Son 
olarak Suriye'deki iç savaşa ve yaşanan krize dikkat çeken Han, radikal İslamclık ile Neoliberalizmi bir madalyonun iki yüzü olarak görür. Almanya'daki bazı ticaret birliklerinin, Almanya'nın ara eleman eksikliğinin mültecilerle tamamlanabilme olasılığının ülkeye fayda sağlayacak bir durum olsa da mültecilerle kurulacak olan ilişkinin niteliğinin yarar hesabına dayanması ahlaki değildir. Ne yazık ki ticari değer noktasına takılan bir hayat kalmamıştır günümüzde. Hiper kapitalist sistemde tüm insan hayatları ve insan ilişkileri ticarileşmiştir. Kant'ın " Edebi Barış " başlıklı yazısında yer alan aklın ve politikanın kaynaştıııması hususu önemlidir. Han'a göre Almanya'nın yerini koruyabilmesi ancak insan onurunu koruyabildiğinde ve aklı öncelikli görevi olarak gördügünnde mümkün olacaktır. Bununla birlikte Han, mülteciler üzerine tartışmanın geri kalan kısmına kendi hayatı üzerinden devam eder. Hannah Arendt'in 1943'te yazdığı " Biz Mülteciler " adlı yazısında, mültecilik kavramını geleneksel rolünden çıkardığı için mutludur. Eskiden kavram, eylem ve siyasi görüşleri sebebiyle sığınacak bir yer arayanları tanımlıyorken, şimdi ceplerinde beş kuruş olmadan başka bir ülkeye gitmek zorunda olan ve mülteci komitelerinin yardımına intiyaç duyan zavalıları tanımlamaktadır Arendt'e göre. Dolayısıyla 'mülteci' kavramının yerini artık 'göçmen' ya da 'yeni gelen' almıştır. Arendt, 'iyimser mülteci' ifadesini kullanır. Daha iyi yaşam adına başka bir ülkeye giden kişilerdir bunlar. Han, kendisini de bu gruba dahil eder. 22 yaşında Kore'de metalürji eğitimini tamamladıktan sonra Almanya'ya edebiyat, felsefe ve teoloji dersleri almaya gitmiştir. İçinde bulunduğu geleneksel yapı ve çevrenin bu eğitimi almaya uygun olmadığını düşündüğü için Almanya'ya geldiğini ifade eder.

Avrupa'yı nasıl düşünmeliyiz? Sınırları nelerdir? Ya da doğrudan Avrupa dediğimiz şey nedir? Coğrafi ya da kavramsal olarak sınırları çizilebilir mi ve bir ideası var mıdır? Bununla birlikte bir şeye özgü olmak nedir? Han hiçbir Koreli'nin bu soruyu sormayacağını ama bir Alman için Alman'a özgülük nedir sorusunun ne olduğunun bir anlamı ve karşı̆ı̆ı olduğunu belirtir. Adorno, " Alman'a özgülük nedir?" adlı yazısında soruya insanlığa geçiş aşaması olarak cevap verir (s.89). Çünkü Alman olmak demek insanlığa bir borcunun ve yükümlülügünün olması demektir. Fakat Han, ötekinin yardımıyla kendine özgü olanın bulunabileceğine inanır. Fransız Başkan Macron'un Frankurt Kitap Fuarı'nda Baudelaire'yi Walter Benjamin sayesinde bulduğunu itiraf etmesi gibi. Bu yüzden kendine özgü olanda yabancının önemi büyüktür. Çünkü birey, kendine özgü olana kör olabilir. Fakat günümüz Avrupa'sı, uzlaşımcı bir yapıya sahip olmayan post-politik bir toplumdur. Han, tüm bu değerlendirmelerden, uygarlıkların huzur yoksunu olduğu ve bir zaman krizi yaşadığı üzerine tartışma başlatır. Özellikle Zamanın Kokusu adlı eserinde üzerinde sıkça durduğu şey günümüz problemlerinden birinin zaman krizi olduğu yönündedir. Zamana sahip olan her şeyin hızlanması mümkün değildir. Ritüeli ve seremonisi olan bir şeye hız kazandırmak o şeye yapılabilecek en büyük haksızıı olur. Çünkü onun kendine özgü bir ritmi ve tınısı vardır. Bir işlemcinin hızını yükseltmek mümkündür fakat bir anlatının hızı yükseltilemez. Ama bunların dışında da bir zaman krizi vardır: Mesai. Yaşamı tek yönlü bir duruma getirmiş bununla birlikte hem hızlandırımış hem de sömürülmüş bir zamandır. Zamandaki anlam, devamlııkla mümkündür. Bireyin kendine ait bir zaman tanımı var mıdır? 
Günümüzde mesai saatleri ve o saatler arasına sıkıştııımış iş molalarından başka zamanlara sahip değiliz. Mesai saati kavramı hayatımızın o denli merkezine yerleşmiştir ki tatillerimizde, uykularımızda hep mesai saati algısı vardır. Fakat hızlanmaya izin vermeyen bir Ben-zamanı vardır. Bu bir başkasına armağan ettiğimiz zamandır. Başkasına verilen zamanda bir hızlandırılma yoktur fakat Neoliberal zaman bunu da tamamen ortadan kaldırmaktadır.

Kitabın sonunda Han'a ait 'Eros Depresyonu Alt Eder' ve 'Kapitalizm Sessizliği Sevmez' adlı iki söyleşisi bulunmaktadır. Bu söyleşi Philosophie Magazin Dergisinden Ronald Düker ve Wolfram Eilenberger ile birlikte yapılmıştır. Söyleşinin temeli Han'ın bundan önceki eserlerinde üzerinde sıkça durduğu olumluluk, olumsuzluk, pornografi toplumu, şeffaflık algısı, performans ve öz sömürü gibi önemli tartışma konuları üzerinden ilerlemiştir. Han'a yöneltilen ilgi çekici sorulardan bir tanesi öteki kavramını daha kullanışı nasıl tanımlanabileceği ve ötekiden çıkış yolunun ne olduğu üzerinedir. Her şeyden önce öteki bir öz saygıdır. Ayrıca öteki bireyi narsistlik duygusundan uzaklaştırandır. Çözüm ise problemin temelinde yatanı dikkatli okumak ile ilgilidir. Eros'un olmadığı bir toplumda öteki yoktur. Kapitalizm Sessizliği Sevmez adlı söyleşisini ise Schaubühne Tiyatrosu'ndan Thomas Ostermeier ve Florian Borchmeyer ile gerçekleştirmiştir. Söyleşinin temelinde kapitalizm ve ölüm dürtüsü ilişkisi devam etmektedir. Fakat buna ek olarak duyguların günümüzdeki yorumu ve bunun tiyatrodaki yerine dikkat çekmektedir. Söyleşinin en dikkat çeken sorularından bir tanesi tiyatroda temel heyecan noktası neden saldırganlıktır? Neden sadece kükrüyorlar? Han'ın bu sorulara cevabını kavramların temeline inmekte görür. Ayrıca duygu ve duygulanım arasındaki farkı belirtmekte bu noktada önemlidir. Duyguda özneler-arasılık olup sosyal bir durumu yansıtıyorken, duygulanım sadece asosyal bir durumu ifade eder. Sahnede oyuncuların bu denli kükremesi onların duygulanımlarla oynuyor olmalarından kaynaklanıyor.

Sonuç olarak Han'ın kapitalizm algısı üzerinden bir ölüm dürtüsü tartışmasına girmesi ilgi çekicidir. Kapitalist sistemin insanın içerisindeki ölüm dürtüsünü ortaya çıkardığı iddiasını Freud'un çıkarımları üzerinden temellendirmeye çalışmıştır. Kapitalizm ve onun sömürgeci yaklaşımı bireyin iç dünyasında ciddi yıkımlara sebep olduğundan kavramın nasıl tanımlanması gerektiği ve ölümle ilişkisi, kitabın üzerinde önemle durduğu ve dikkatle tartışığı bir husus olmuştur. Kapitalizmi sermaye birikimine zorlayan şeyin ölüm dürtüsü olduğu iddiası çok yerinde bir tespittir. İçinde yaşadığımız dünyada insanların hunharca bir şeyleri biriktirme arzusu aslında yüzleşmek istemedikleri ölümle doğrudan ilgilidir. Çünkü insan yaşamı ve iç dünyası, Han'ın da tespitini detaylı bir şekilde belirttiği gibi birikmiş olan sermaye ile kendini koruyabildiği içgüdüsüne sahiptir. Bu denli güçlü bir arzunun üretimi hızlandırması ve kapitalizmi büyütmesi elbette kaçınılmaz. Fakat gözden kaçırılmaması gereken bir diğer husus kapitalizmin hızını etkin kılan durumlardan birinin performans öznesi olduğu hususudur. Diğer kitaplarında üzerinde sıkça durduğu performans öznesi kavramının anlaşılması önemlidir. Çünkü kavram, kendini sömüren, depresif ve narsist kişiler haline dönüşmüş zombileri 
temsil etmektedir. Kendine bu denli yabancılaşmış olan bireyin kapitalist sisteme köle olması elbette kaçınılmaz bir durumdur. Bununla birlikte gözden kaçmaması gereken bir durumu Han özellikle belirtmiştir. Big Data, hem günümüz öznesini performans öznesi olarak var etmeye devam ettirebilmek için hızla gücünü arttırmaya devam ederken, hem de kapitalizme Big Data üzerinden daha geniş bir tanım aralığı çizmektedir. Kitabın en önemli noktası Han'ın üzerinde tartıştığı konuları kendi kavramları ile açıklıyor olmasıdır. Aynı zamanda Hannah Arendt'ın mülteci kavramı yerine göçmen ve yeni gelen ifadelerini kullanmasını olumlu değerlendirir. Fakat Han'ın gözden kaçırdığı durum göçmen algısı üzerine devam eden bir durumun olduğudur. Çünkü Han, kavramı eylem ve söylemleri sebebiyle ülkesini terk edenlerden, kendine yeni bir hayat isteyen insanlara evrildiği düşüncesi üzerinden tanımlamaktadır. Bu hususa katımak kavramı daraltabileceği için eleştiriye açıktır. Üzerinde durduğu bir diğer önemli tartışma konusu Ben-zaman kavramıdır. Neoliberal zamanın Ben-zamanı da ortadan kaldırdığını belirtir. Böyle bir zamanın ortadan kalktığını ifade etmek genel bir yaklaşım olabilir. Çünkü ne kadar kendimize ayırdığımız zaman kaybolmaya yakın olsa da buna bir direnç olduğunu inkâr etmek doğru olmayacaktır. Genel itibariyle eser, kapitalizmi ölüm dürtüsü algısı üzerinden değerlendirmesi noktasında kıymetlidir. Aynı zamanda iddialarını kendi kavramları üzerinden değerlendirmesi ve bazı kavramları da geleneksel algıların dışına taşıması noktasında da önem taşımaktadır. 